\title{
Identifikasi Intrusi Air Laut Dengan Menggunakan Metode Geolistrik Konfigurasi Wenner - Schlumberger di Daerah Malalayang Sulawesi Utara
}

\author{
Obed Salu Pasamba' a*,Gerald H. Tamuntuan a,Adey Tanauma a \\ aJurusan Fisika, FMIPA, Unsrat, Manado \\ KATA KUNCI \\ A B S T R A K
}

Geolistrik

Intrusi Air Laut

Konfigurasi Wenner -

Schlumberger

\begin{abstract}
Telah dilakukan penelitian eksplorasi geofisika menggunakan metode Geolistrik Konfigurasi Wenner - Schlumberger untuk mengindentifikasi lapisan tanah yang diduga terkena intrusi air laut di daerah Malalayang Sulawesi Utara. Terdapat 5 lintasan pengukuran dan pada setiap lintasan mempunyai 112 dan 167 buah data. Data setiap lintasan diolah menggunakan perangkat lunak RES2DINV. Dugaan intrusi air laut terjadi di daerah Malalayang I Timur sejauh $\leq 300$ meter dari garis pantai dengan kedalaman $\geq 10$ meter di bawah permukaan tanah dan di daerah Malalayang II sejauh 310 meter dari garis pantai dengan kedalaman $\geq 20$ meter di bawah permukaan tanah.

A B S T R A C T

Geophysical exploration has been conducted using Geoelectric method of Wenner - Schlumberger Configuration to identify the soil layers suspected of being exposed to seawater intrusion in Malalayang of North Sulawesi. There are 5 measurement lines and each line has 112 and 167 data. The data of each line is processed using RES2DINV software. Suspected seawater intrusion is located in the East Malalayang I area as far as $\leq 300$ meters from the coastline with a depth of $\geq 10$ meters under ground surface and in Malalayang II area as far as 310 meters from the coastline with a depth of $\geq 20$ meters under ground surface.
\end{abstract}

K E Y W O R D S

Geoelectrical

Seawater Intrusion

Wenner - Schlumberger

Configuration
TERSEDIAONLINE

Oktober 2017
1. Pendahuluan

Air tanah merupakan kebutuhan vital dan pokok di seluruh negara. Beberapa faktor yang mempengaruhi kualitas reservoir air tanah, yaitu terkontaminasi oleh penyusupan air laut (Harding, 1991) dan zat beracun akibat pembuangan industri (Barker, 1996). Penyusupan atau intrusi air laut ke dalam akuifer daerah pantai sudah lama menjadi keprihatinan dunia. Intrusi terjadi sebagai akibat dari aliran induksi air laut ke dalam akuifer air tawar yang awalnya disebabkan oleh penyerapan (pemompaan) air tanah di daerah pantai (Al Barwani and Helmi, 2006).Intrusi air laut merupakan masalah bagi lingkungan di sekitarnya yang memerlukan metode yang sesuai untuk menangani dampak masalah ini (Bernstone and Dahlin, 1996).Metode kelistrikan dan elektromagnetik telah menjadi bidang aplikasi geofisika terpenting selama sekitar satu abad, terutama untuk penyelidikan dangkal dan dekat permukaan.Sejak saat itu, survei geolistrik tahanan jenis sangat meningkat dan menjadi alat yang penting dan berguna dalam studi hidrogeologi, prospeksi mineral dan pertambangan, serta aplikasi lingkungan dan rekayasa(Griffiths et al., 1990; Griffiths dan Barker, 1993). Berdasarkan hasil survei yang ada menunjukkan bahwa masyarakat lebih cenderung memakai sumur pompa (75\%) dibandingkan PT. Air (25\%) (Fakultas Kedokteran Komunitas dan Tropik, 2013). Berdasarkan uraian di atas, maka dilakukan penelitian tentang intrusi air laut di Daerah Malalayang Sulawesi Utara.

Intrusi Air Laut

Intrusi air laut adalah perpindahan air laut ke daerah yang sebelumnya diduduki oleh air tawar.Karena berat jenis air laut sedikit lebih besar

*Corresponding author: Jurusan Fisika FMIPA UNSRAT, Jl. Kampus Unsrat, Manado, Indonesia 95115; Email address: obedsalupasamba@gmail.com Published by FMIPA UNSRAT (2017) 
dari pada berat jenis air tawar maka air laut akan mendesak air tawar di dalam tanah lebih ke hulu. ketinggian muka air dan dalamnya daerah transisi dapat dicari dengan menggunakan Persamaan Ghyben-Herzberg. Persamaan ini dapat dicari sebagai berikut:

$$
(h+z) \gamma_{\mathrm{f}}=z \gamma_{\mathrm{s}} \text { atau } z=40 h_{\mathrm{f}}
$$

di mana

$h_{\mathrm{f}}=$ ketinggian air tawar (elevasi muka air tanah) (m)

$z=$ kedalaman daerah transisi di bawah muka air laut $(\mathrm{m})$

$\gamma_{\mathrm{f}}=$ massa jenis air tawar $\cong 1000 \mathrm{~kg} / \mathrm{m}^{3}$

$\gamma_{\mathrm{s}}=$ massa jenis air asin $\cong 1025 \mathrm{~kg} / \mathrm{m}^{3}$

\section{Aliran Air Tanah}

Chebotarev (1955) menyimpulkan bahwa aliran air tanah cenderung mengubah secara perlahan komposisi kimia air yang ada dari hulu ke hilir dan mengarah pada komposisi kimia air laut.

\section{Geolistrik}

Pengukuran geolistrik dilakukan dengan cara merekam potensial listrik yang timbul dari arus masukan ke dalam tanah dengan tujuan mencapai informasi pada struktur resistivitas di bawah tanah.

\section{Sifat Kelistrikan Batuan dan Mineral}

Aliran konduksi arus listrik didalam batuan/mineral digolongkan atas tiga macam yaitu konduksi dielektrik, konduksi elektrolitik, dan konduksi elektronik.

\section{Konfigurasi Wenner - Schlumberger}

Wenner - Schlumberger merupakan metode gabungan antara konfigurasi wenner dan schlumberger. Schlumberger merupakan konfigurasi elektroda metode geolistrik yang sudah umum digunakan untuk sounding atau kedalaman.

\section{Material dan Metode}

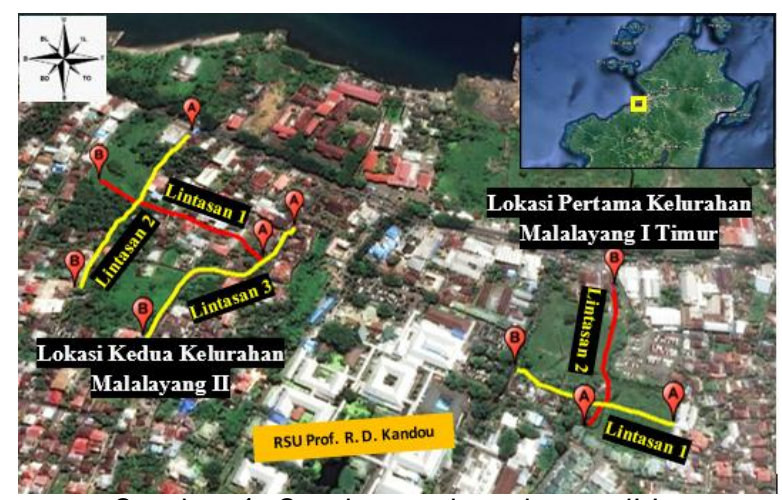

Gambar 1. Gambaran daerah penelitian

Penelitian telah dilaksanakan dengan proses pengamatan dan pengukuran secara langsung di Daerah Malalayang Sulawesi Utara. Pengambilan data dilakukan pada tanggal 25 - 26 Mei 2017.

Alat yang digunakan dalam penelitian ini adalah: Alat geolistrik resistivitymeter: Multi-Channel and Multi-Electrode Resistivity and IP Meter MAE X612-EM, Global Postioning System: Garmin, Laptop: Laptop Lenovo AMD A8-6410, Software
RES2DINV, Software Notepad, Refractometer dan bahan yang digunakan adalah peta Google Earth.

\section{Hasil dan Pembahasan}

Model kontur nilai resistivitas yang telah diperoleh dari pengolahan data dapat digunakan untuk menganalisis dugaan intrusi air laut. Namun nilai resistivitas tidak cukup untuk menganalisis dugaan intrusi air laut. Oleh sebab itu, dalam analisis ini ditambahkan data dari kadar salinitas air pada sumur - sumur yang dilewati oleh lintasan pengukuran.

Dugaan Intrusi Air Laut di Kelurahan Malalayang I Timur

Tabel 1. Data sumur - sumur yang dilewati oleh lintasan pengukuran di Malalayang I Timur

\begin{tabular}{|c|c|c|c|}
\hline Sumur & $\begin{array}{c}\text { Kedalaman dasar } \\
\text { sumur dari } \\
\text { permukaan } \\
\text { tanah }(\mathrm{m})\end{array}$ & $\begin{array}{c}\text { Kedalaman } \\
\text { permukaan air } \\
\text { sumur dari } \\
\text { permukaan tanah } \\
(\mathrm{m})\end{array}$ & $\begin{array}{c}\text { Salinitas } \\
(\%)\end{array}$ \\
\hline Sumur 1 & 2 & 0 & 0 \\
\hline Sumur 2 & 2 & 0,1 & 0 \\
\hline Sumur 3 & 3 & 0,1 & 0 \\
\hline Sumur 4 & 3 & 1 & $\leq 0,1$ \\
\hline
\end{tabular}

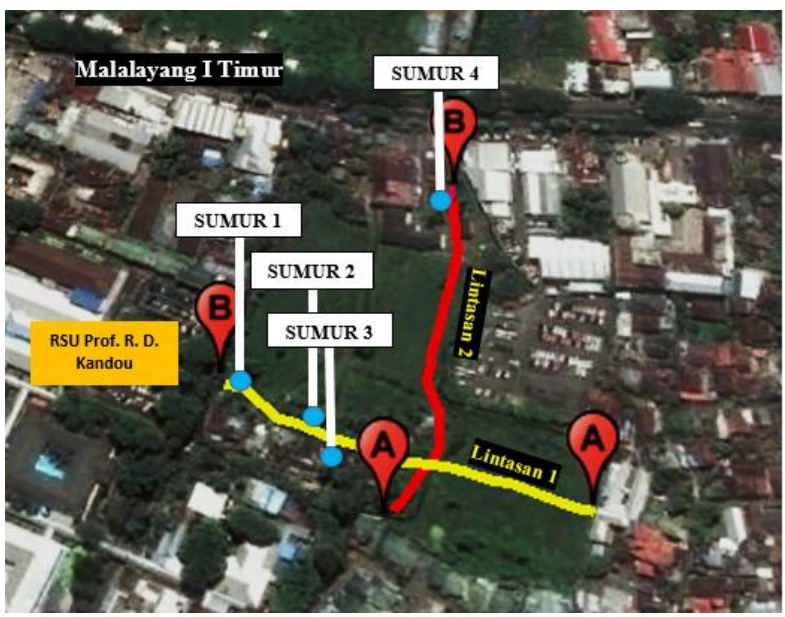

Gambar 2. Letak sumur - sumur pada Malalayang I Timur

Berdasarkan data - data yang diperoleh, maka dapat dilakukan analisis intrusi air laut pada lintasan 1. Pada meter ke 140 sampai meter ke 160 terdapat lapisan yang memiliki citra warna biru tua dan pada meter ke 190 sampai meter ke 210 dengan nilai resistivitas $\leq 1,45 \Omega \mathrm{m}$. Nilai resistivitas tersebut tergolong air payau. Setelah dilakukan pengukuran salinitas air pada sumur - sumur (1, 2, 3) yang dilalui oleh lintasan ini seperti pada Gambar 2 , diperoleh kadar salinitas $0 \%$ yang ditunjukkan pada table 1 . Sumur - sumur tersebut terdapat pada meter ke 155, meter ke 180 dan meter ke 235. Berat jenis air laut lebih besar dari pada berat jenis air tawar yang berarti posisi air laut atau air payau berada di bawah air tawar. Namun pada lintasan ini, lapisan yang memiliki nilai resistivitas $\leq 1,45 \Omega \mathrm{m}$ berada dekat permukaan tanah dan posisinya lebih tinggi dari lapisan yang mengandung 
air tawar serta lapisan tersebut berjarak sejauh 450 meter dari garis pantai. Berdasarkan hasil tersebut, maka pada lapisan ini diduga tidak terkena intrusi air laut. Maka lapisan yang memiliki nilai resistivitas $\leq 10 \Omega \mathrm{m}$ dapat diduga merupakan lapisan yang mengandung air yang berkualitas rendah.

Pada linatasan 2, lapisan yang memiliki citra warna biru dengan nilai resistivitas $\leq 1,45 \Omega$ m yang tergolong air payau pada meter ke 170 sampai meter ke 190. Lapisan tersebut berada dekat pantai sejauh 300 meter dari garis pantai dan kedalamannya sejajar bahkan berada di bawah garis pemukaan air laut. Pada lintasan ini terdapat satu sumur (sumur 4) pada meter ke 230 yang memiliki kedalaman 3 meter mengandung kadar salinitas air $\leq 0,1 \%$. Berdasarkan kedua data tersebut, dapat diduga lapisan ini telah mengalami intrusi air laut. Penyebaran intrusi air laut dapat dilihat pada Gambar 4.8 yang ditunjukkan oleh anak panah. Pada meter ke 40 merupakan titik perpotongan lintasan 1 dan 2 yang memiliki lapisan dengan nilai resistivitas $\leq 4,18 \Omega \mathrm{m}$. Karena lapisan pada lintasan 1 tidak mengalami intrusi air laut, maka pada titik perpotongan ini juga tidak mengalami intrusi air laut. Pada meter ke 90 sampai meter ke 120 merupakan lapisan yang mengandung air tanah.

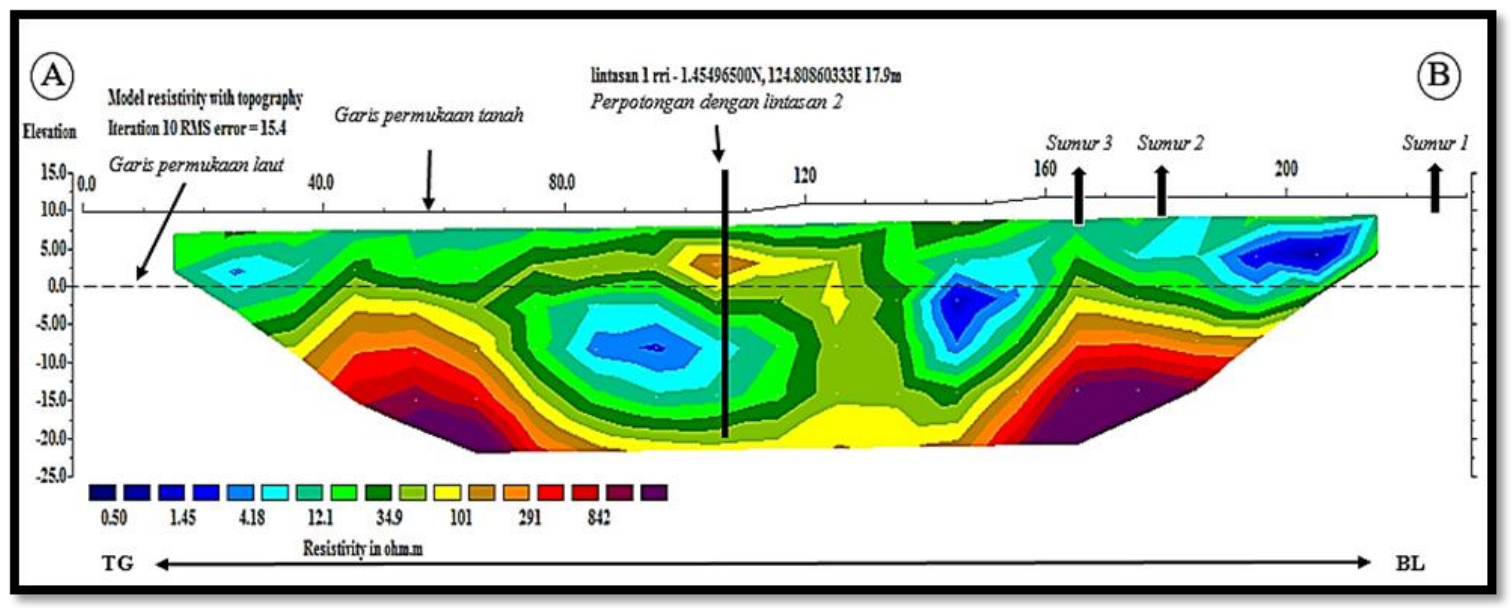

Gambar 3. Analisis intrusi air laut lintasan 1 Kelurahan Malalayang I Timur

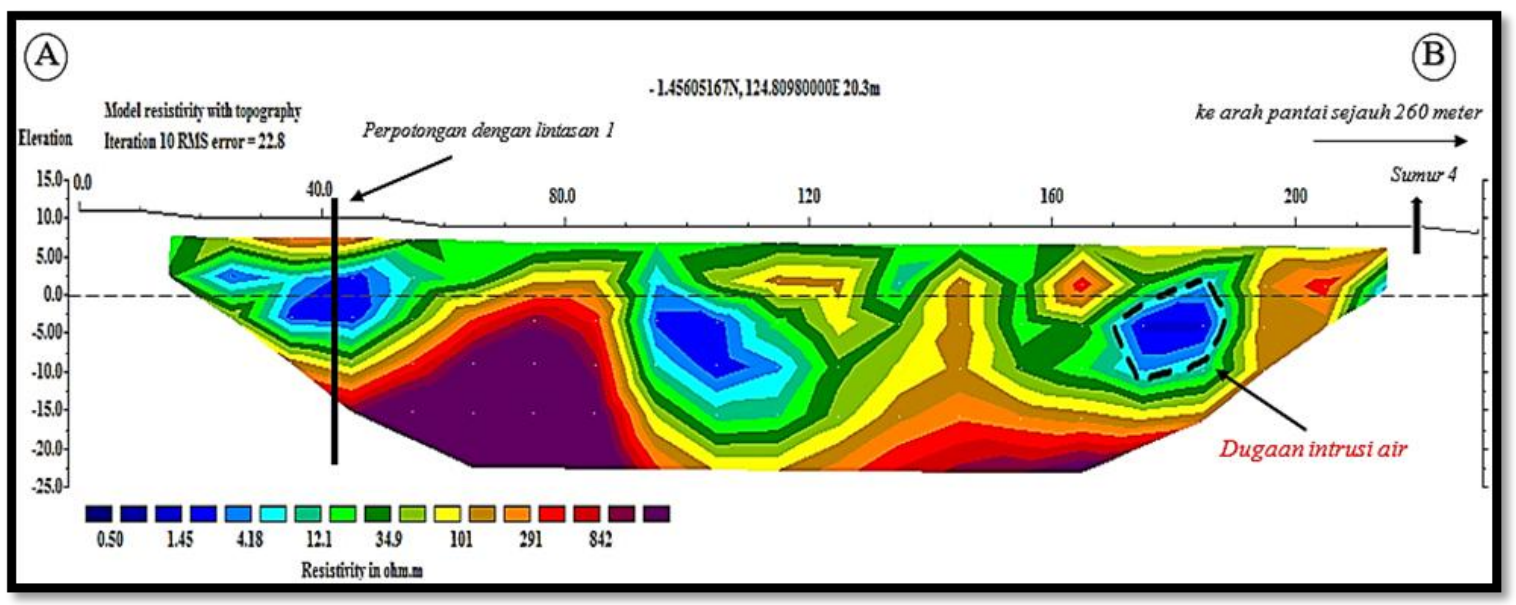

Gambar 4.Analisis intrusi air laut lintasan 2 Kelurahan Malalayang I Timur

\section{Dugaan Intrusi Air Laut di Kelurahan Malalayang II}

Pada lintasan 1, terdapat citra warna biru tua dengan nilai resistivitas $\leq 1,45 \Omega$ m yang tergolong air payau. Setalah dilakukan pengukuran salinitas air pada sumur ( $5 \& 6$ ) yang dilalui oleh lintasan ini seperti pada Gambar 4.10, diperoleh kadar salinitas $0 \%$ untuk sumur 5 dan $\leq 0,1 \%$ untuk sumur 6 . Sumur 5 berjarak 6 meter datar lintasan 1 ke arah timur laut dengan kedalaman 6 meter dan sumur 6 berjarak 6 meter dari lintasan 1 ke arah barat daya dengan kedalaman 10 meter. Berdasarkan data data tersebut dapat diduga lapisan yang memiliki citra warna biru pada meter ke 135 sampai meter ke 180 telah mengalami intrusi air laut seperti yang ditunjukkan pada Gambar 4.11. Pada lintasan ini, intrusi air laut terjadi pada kedalaman 10 meter bawah permukaan tanah atau 5 meter di atas permukaan laut.

Lapisan yang terdapat pada lintasan 2 didominasi oleh lapisan keras seperti terlihat pada Gambar 4.12. Pada meter ke 170 sampai meter ke 190 terdapat lapisan yang memiliki citra warna biru dengan nilai resistivitas $\leq 12,1 \Omega \mathrm{m}$ merupakan lapisan yang mengandung air tanah. Pada meter ke 205 sampai meter ke 225 terdapat lapisan yang memiliki citra warna biru dengan nilai resistivitas $\leq$ 
1,45 $\Omega \mathrm{m}$ merupakan lapisan yang mengandung air berkualitas rendah. Pada lintasan ini terdapat sumur (sumur 7) yang berjarak 10 meter dari lintasan ini seperti pada gambar 4.10 yang memiliki kedalaman 10 meter bawah permukaan tanah dan kadar salinitas $0 \%$. Sehingga pada lintasan ini tidak ditemukan adanya intrusi air laut.

Tabel 2. Data sumur - sumur yang dilewati oleh lintasan pengukuran di Malalayang II

\begin{tabular}{|c|c|c|c|}
\hline Sumur & $\begin{array}{c}\text { Kedalaman } \\
\text { dasar sumur dari } \\
\text { permukaan } \\
\text { tanah }(\mathrm{m})\end{array}$ & $\begin{array}{c}\text { Kedalaman } \\
\text { permukaan air } \\
\text { sumur dari } \\
\text { permukaan } \\
\text { tanah }(\mathrm{m})\end{array}$ & $\begin{array}{c}\text { Salinitas } \\
(\%)\end{array}$ \\
\hline Sumur 5 & 6 & 3 & 0 \\
\hline Sumur 6 & 10 & 5 & $\leq 0,1$ \\
\hline Sumur 7 & 10 & 6 & 0 \\
\hline
\end{tabular}

Lapisan yang terdapat pada lintasan 2 didominasi oleh lapisan keras seperti terlihat pada Gambar 4.12. Pada meter ke 170 sampai meter ke 190 terdapat lapisan yang memiliki citra warna biru dengan nilai resistivitas $\leq 12,1 \Omega \mathrm{m}$ merupakan lapisan yang mengandung air tanah. Pada meter ke 205 sampai meter ke 225 terdapat lapisan yang memiliki citra warna biru dengan nilai resistivitas $\leq$ $1,45 \Omega$ merupakan lapisan yang mengandung air berkualitas rendah. Pada lintasan ini terdapat sumur (sumur 7) yang berjarak 10 meter dari lintasan ini seperti pada gambar 4.10 yang memiliki kedalaman 10 meter bawah permukaan tanah dan kadar salinitas $0 \%$. Sehingga pada lintasan ini tidak ditemukan adanya intrusi air laut.

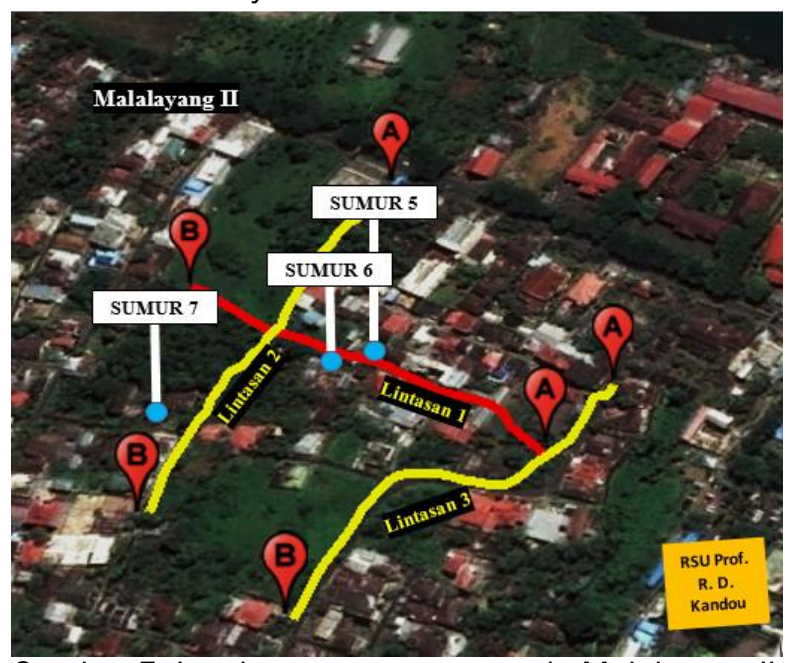

Gambar 5. Letak sumur - sumur pada Malalayang II

Pada lintasan 3, lapisan yang memiliki citra warna biru dengan nilai resistivitas hingga $\leq 1,45 \Omega$ m pada meter ke 80 sampai meter ke 100 seperti terlihat pada gambar 4.13. Pada lintasan ini tidak ditemukan adanya sumur untuk dilakukan pengukuran kadar salinitas air. Namun lapisan tersebut berada dekat pantai yang kedalamannya sejajar hingga di bawah permukaan laut dan sejajar dengan lapisan yang mengalami intrusi air laut pada lintasan 1. Sehingga pada lapisan tersebut dapat diduga telah mengalami intrusi air laut seperti pada Gambar 4.13.

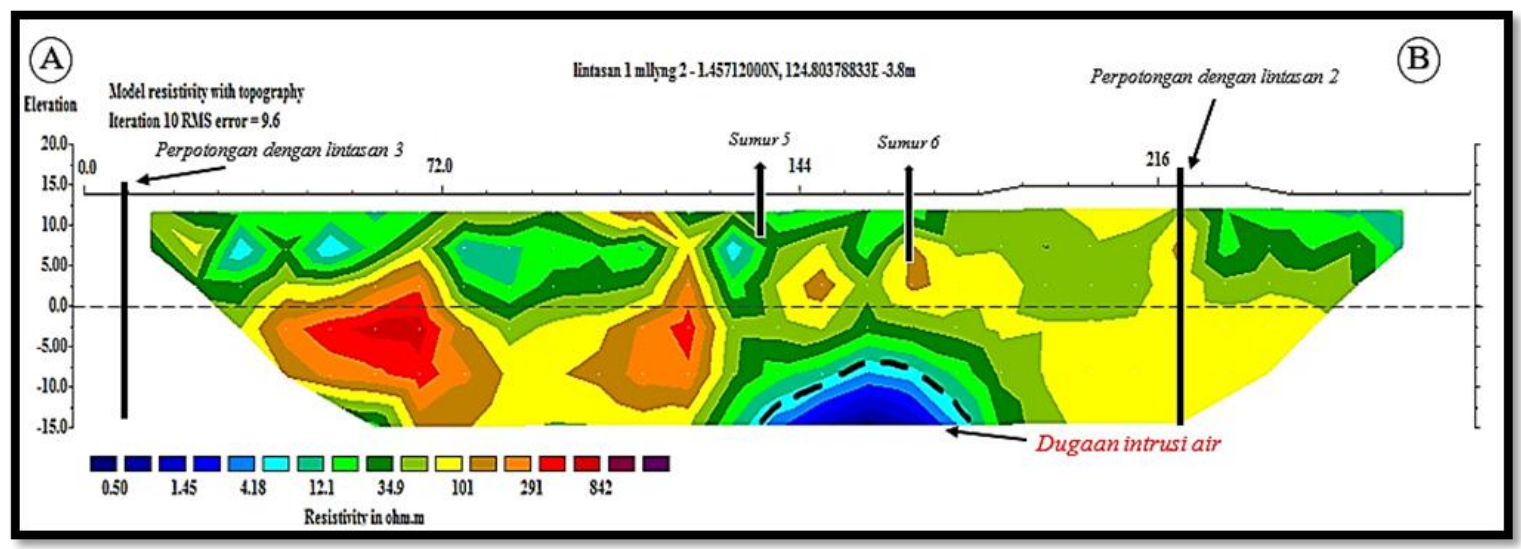

Gambar 6. Analisis intrusi air laut lintasan 1 Kelurahan Malalayang II(sejajar pantai sejauh $310 \mathrm{~m}$ )

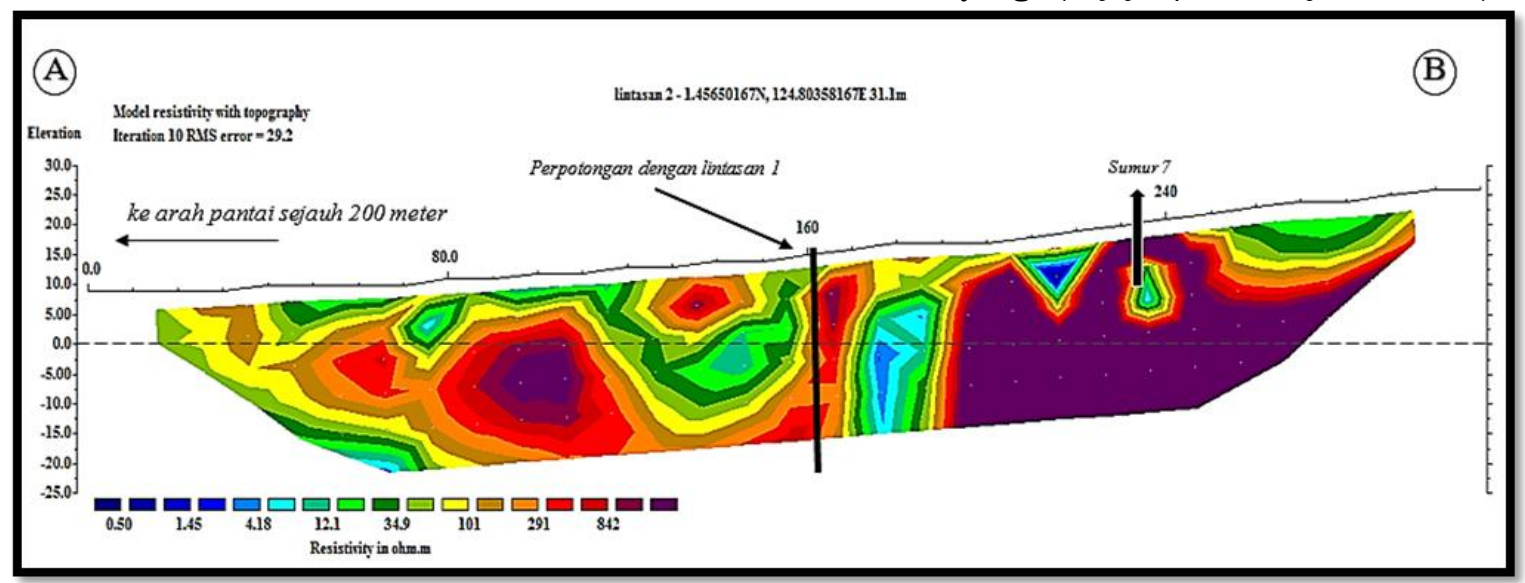

Gambar 7. Analisis intrusi air laut lintasan 2 Kelurahan Malalayang II 


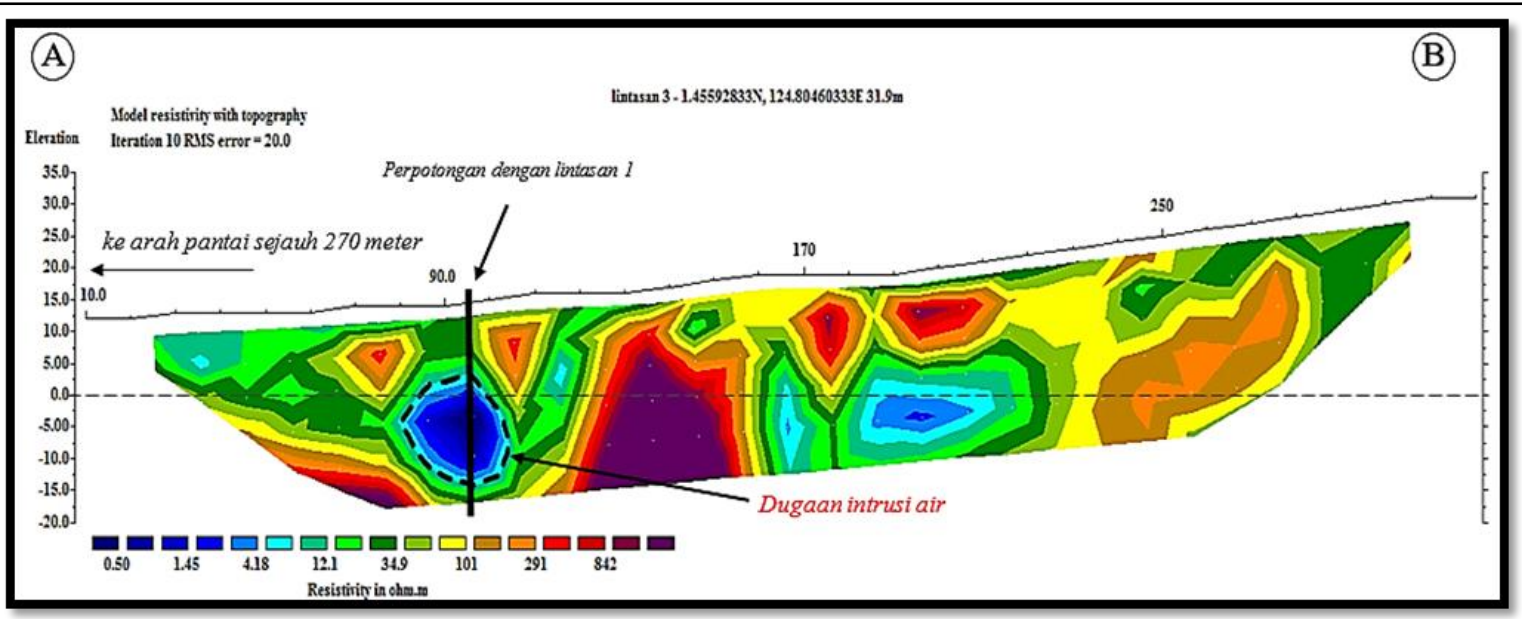

Gambar 8. Analisis intrusi air laut lintasan 3 Kelurahan Malalayang II

\section{Kesimpulan}

Telah diteliti pendugaan intrusi air laut di daerah Malalayang Sulawesi Utara dengan menggunakan metode geolistrik tahanan jenis konfigurasi wenner - schlumberger. Diduga adanya intrusi air laut di daerah Malalayang I Timur sejauh $\leq$ 300 meter dari garis pantai dengan kedalaman $\geq 10$ meter di bawah permukaan tanah dan di daerah Malalayang II sejauh 310 meter dari garis pantai dengan kedalaman $\geq 20$ meter di bawah permukaan tanah.

\section{Daftar Pustaka}

Al Barwani, A. and Helmi, T. 2006. Seawater Intrusion In A Coastal Aquifer: A Case Study For The Area Between Seeb and Suwaiq in the Sultanate of Oman. Agric. Mar. Sci.11:55-69.

Barker, R. D. 1996. The Application Of Electrical Tomography In Groundwater Contamination Studies. Extended Abstracts, p. 82, 58th EAGE conference, Amsterdam.

Bear, J., Cheng, A. H. D., et al. 1999. Seawater Intrusion in Coastal Aquifers; concept, method and practices. Kluwer Academic Publishers. Dordrecht.

Bernstone, C. and Dahlin, T. 1996. Electromagnetic And DC Resistivity Mapping Of Waste Deposits
And Industrial Sites \pm Experiences From Southern Sweden. Extended Abstracts, M014, 58th EAGE Conference, Amsterdam.

Cheboratev, I. I. 1955. Metamorphism of Natural Water in The Crust of Weathering-1. Geochimica et Cosmochimica Acta. 8(1-2): 22 - 32.

Fakultas Kedokteran Komunitas dan Tropik. 2013. Gambaran Penggunaan Air Bersih Di Kelurahan Malalayang I Kota Manado. Fakultas Kedokteran, Unsrat, Manado.

Griffiths, D. H. and Barker, R. D. 1993. Two Dimensional Resistivity Imaging And Modelling In Areas Of Complex Geology. J. Appl. Geophy. 29: 211- 226.

Griffiths, D. H., Turnbull, J. and Olayinka A. I. 1990. Two-Dimensional Resistivity Mapping With A Complex Controlled Array. First Break.8: 121129.

Harding, R. 1991. The saline groundwater of the Sow Valley, and of the Upper Trent Valley near Weston [MSc thesis]. University of Birmingham, Birmingham.

Telford, W. M., Geldart, L.P., Sheriff, R.E. and Keys, D. A. 1990. Applied Geophysic. Cambridge University Press, London. 